\title{
SABERES DISCIPLINARES QUE ORIENTARAM A FORMACÃO NO CURSO NORMAL DA ESCOLA SUPERIOR DE EDUCAÇÃO FÍSICA DO RIO GRANDE DO SUL (1940-1956)
}

\author{
TUANY DEFAVERI BEGOSSI' \\ ORCID: https://orcid.org/0000-0002-2596-5963 \\ JANICE ZARPELLON MAZO' \\ ORCID: https://orcid.org/0000-0002-8215-0058. \\ DENISE GROSSO DA FONSECA' \\ ORCID: https://orcid.org/0000-0001-6206-4729
}

I Universidade Federal do Rio Grande do Sul, Porto Alegre, RS, Brasil.

RESUMO: O objetivo do presente estudo foi compreender as composições dos saberes disciplinares que orientaram a formação no Curso Normal da Escola Superior de Educação Física (ESEF), do estado do Rio Grande do Sul, no período de 1940 a 1956. O recorte temporal envolve o ano de 1940, quando o Curso Normal entrou em funcionamento, até 1956, o último ano em que foi oferecido, sendo substituído, no ano seguinte, pelo curso de Educação Física Infantil. A interpretação dos materiais de pesquisa, sustentada pelos referenciais teórico-metodológicos dos Saberes Disciplinares e da História Cultural, nos levou a identificar influências que traduziam ao ambiente de ensino do Curso Normal, orientações de um caráter militarizado, expressas através do Método Francês. Ao lado deste, também figurou a emergência de novas formas de se pensar e fazer Educação Física no estado, demarcando a presença de um caráter pedagógico à formação.

Palavras-chave: História da Educação Física. Formação de professores. Escola Superior de Educação Física do estado do Rio Grande do Sul; Curso Normal. Saberes Disciplinares.

Tuany D. Begossi - Doutoranda no Programa de Pós-Graduação em Ciências do Movimento Humano (PPGCMH), da Universidade Federal do Rio Grande do Sul (UFRGS). Mestra em Ciências do Movimento Humano (PPGCMH/UFRGS). Integrante do Núcleo de Estudos em História do Esporte e da Educação Física (NEHME/UFRGS). E-mail:< tuany_begossi@hotmail.com>.

Janice Z. Mazo - Doutora em Ciências do Desporto pela Universidade do Porto (UP). Professora associada da Escola de Educação Física, Fisioterapia e Dança (ESEFID) e do Programa de Pós-Graduação em Ciências do Movimento Humano (PPGCMH), da Universidade Federal do Rio Grande do Sul (UFRGS). Coordenadora do Núcleo de Estudos em História do Esporte e da Educação Física (NEHME/UFRGS).

E-mail:<janice.mazo@ufrgs.br >.

Denise G. da Fonseca - Doutora em Educação pela Universidade do Vale do Rio dos Sinos (UNISINOS). Professora da Escola de Educação Física, Fisioterapia e Dança (ESEFID), da Universidade Federal do Rio Grande do Sul (UFRGS). Coordenadora do Grupo de Estudos em Docência e Avaliação em Educação Física (GEDAEF).

E-mail:<dgf.ez@terra.com.br >. 


\section{DISCIPLINARY KNOWLEDGE THAT ORIENTED THE TRAINING IN THE NORMAL COURSE OF THE SCHOOL OF PHYSICAL EDUCATION OF RIO GRANDE DO SUL (1940-1956)}

ABSTRACT: The objective of the present study was to understand the compositions of the disciplinary knowledge oriented the training in the Curso Normal da Escola Superior de Educasão Física (ESEF), in the state of Rio Grande do Sul, from 1940 to 1956. The temporal cutting involves the year 1940, when the Regular Course began its operation, until 1956, the last year when it was offered, being replaced in the following year by the course of Physical Education for Children. The interpretation of research materials, based by theoretical-methodological references of Disciplinary Knowledge and Cultural History, led us to identify influences that translated into the teaching environment of the Normal Course, orientations of a militarized character expressed through the French Method. Alongside this, also appeared the emergence of new ways of thinking and doing Physical Education in the state, demarcating the presence of a pedagogical character to the formation.

Keywords: History of Physical Education. Teacher qualification. Escola Superior de Educacão Física (ESEF) of the state of Rio Grande do Sul. Normal Course. Disciplinary Knowledge.

\section{INTRODUÇÃO}

O Curso Normal da Escola Superior de Educação Física (ESEF), atual Escola de Educação Física, Fisioterapia e Dança (ESEFID), da Universidade Federal do Rio Grande do Sul (UFRGS), entrou em funcionamento juntamente com as demais atividades da instituição, no ano de 1940. Na época, subordinada ao Departamento de Educação Física do estado (DEEF), a ESEF, através de seu Curso Normal, proveu as escolas do Rio Grande do Sul com professores(as) de Educação Física durante os 16 anos de funcionamento do referido curso (1940-1956). Aliado a isso, evidenciamos que a ESEF é considerada escola pioneira no estado, no oferecimento de uma formação específica na área (LYRA, 2013).

O Curso Normal foi composto por disciplinas, as quais deveriam ser cursadas, inicialmente, durante o período de um ano (BEGOSSI, 2017). As ações de ensino da referida formação foram orientadas por objetivos, conteúdos programáticos e sequências de aprendizado, delineadas nos programas de ensino de cada um dos saberes disciplinares que compunham a totalidade do Curso Normal. Nesse sentido, tais 
materiais se apresentaram a nossa investigação enquanto documentos pedagógicos, portadores de um caráter de organização da ação educativa, orientadores das práticas de ensino dos docentes.

Para além do caráter orientador dos programas de ensino, os conteúdos neles localizados apresentavam determinadas características que refletiam, de certa forma, os preceitos circulantes nos cursos de formação de professores(as) de Educação Física da época. Diante do exposto, o presente estudo tem por objetivo compreender as composições dos saberes disciplinares que orientaram a formação no Curso Normal, da Escola Superior de Educação Física (ESEF), do estado do Rio Grande do Sul, no período de 1940 a 1956. O recorte temporal do estudo parte do ano de 1940, quando o Curso Normal de Educação Física entrou em funcionamento, juntamente com as demais atividades da ESEF, e se encerra no ano de 1956, último ano de vigência do Curso Normal, visto que fora substituído pelo Curso de Educação Física Infantil a partir do ano de 1957.

Para sustentar as linhas desta investigação, elegemos dois pilares teórico-metodológicos. O primeiro deles se apresentou por meio da obra de Maurice Tardif, intitulada "Saberes docentes e formação profissional” (2014). Para o autor (2014), o saber docente se compõe de vários outros tipos de saberes, podendo ser disciplinares, curriculares, profissionais e experienciais. À nossa investigação interessaram aqueles conceituados como saberes disciplinares, os quais são provenientes da tradição cultural, sendo definidos e selecionados pela instituição universitária (TARDIF, 2014).

De modo semelhante, Desbiens (2005) nos diz que os saberes disciplinares são produzidos dentro de um contexto histórico e social, que a eles exprime e testemunha modos de socialização e de apropriação. Para o autor (2005), qualquer forma de análise relacionada a esses conhecimentos não pode ser feita com a abstração total de fatores contextuais, exteriores ou interiores à instituição de ensino. Diante disso, as orientações dos autores (DESBIENS, 2005; TARDIF, 2014) voltamse à importância de identificar elementos que constituem o ambiente da atividade docente, para que se evidencie, dentro do possível, a influência desses aspectos na construção, desenvolvimento e estruturação dos saberes profissionais, especialmente daqueles ditos disciplinares.

Nessa direção, se fez necessário compreendermos o contexto de ensino do Curso Normal da ESEF, bem como as influências presentes no campo da formação de professores(as) de Educação Física do período. Para tanto, o segundo pilar teórico-metodológico 
desta investigação, referente à História Cultural (PESAVENTO, 2004; CHARTIER, 2006, 2010, 2017), nos auxiliou neste entendimento, tornando possível a compreensão das diferentes dimensões que confluíram para o estabelecimento de saberes disciplinares próprios à formação do professorado da ESEF. De modo pontual, o conceito de representações balizou a interpretação dos documentos eleitos ao estudo e nos permitiu refletir acerca da "articulação entre os discursos e as práticas" que, segundo Chartier (2017, p. 47), trata-se do principal desafio apresentado à História Cultural.

Para esse autor (2017, p. 51), "as representações não são simples imagens, verdadeiras ou falsas, de uma realidade que lhes seria externa; elas possuem uma energia própria que leva a crer que o mundo ou o passado é, efetivamente, o que dizem que é". Nesse sentido, a construção do presente estudo foi norteada pelos vestígios apresentados pelos documentos de pesquisa eleitos, bem como pelas leituras que estes nos permitiram fabricar acerca da realidade demarcada à investigação (GINZBURG, 1989; CHARTIER, 2017). O texto apresentado, dessa forma, corresponde a uma narrativa do passado, sendo essa uma possível representação da realidade (CHARTIER, 2010).

Para efetivação do estudo e com o intuito de atender ao objetivo proposto, foram analisados documentos, sendo esses cotejados com o material bibliográfico reunido para a pesquisa. $\mathrm{O}$ corpus documental foi composto pelos programas de ensino das disciplinas do Curso Normal da ESEF, pelo Regimento Interno do DEEF e pela documentação legal relacionada à Educação Física da época. Para além desses, contamos com um conjunto de documentos orais, constituído por entrevistas transcritas, realizadas com ex-alunas e ex-professoras do Curso Normal da ESEF. Para Verena Alberti (2005, p. 24), os "documentos orais" são entrevistas que, depois de transcritas, se transformam em documentos, que passam a representar uma interpretação do passado, atualizada através da linguagem falada.

Os acima mencionados materiais de pesquisa foram interpretados através da técnica de análise documental (BACELLAR, 2010). Em seguida, por meio do cotejamento desses materiais, foi possível construirmos uma narrativa historiográfica, cujos resultados são apresentados nos tópicos que seguem.

\section{O CARÁTER MILITAR NOS SABERES DISCIPLINARES}

O Curso Normal de Educação Física da ESEF (1940-1956) foi o primeiro desse nível a ser instituído no cenário sul-rio-grandense. 
Tendo por desígnio basilar a formação de professores(as) para atuação junto das escolas estaduais, os(as) candidatos(as) interessados em cursá-lo precisavam apresentar o diploma de normalista, ou seja, o documento que comprovava a conclusão dos estudos em escolas normais. Como característica ordinária entre os(as) normalistas estava o trabalho desenvolvido junto às instituições de ensino estaduais, localizadas em cidades no interior do estado. A motivação para buscar a formação na ESEF se situava, principalmente, na possibilidade de se aperfeiçoarem em um (novo) campo de atuação e, nesta mesma direção, sanar a necessidade que havia na época de professores(as) de Educação Física (BEGOSSI, 2017).

O período de estudos do curso era, inicialmente, de um ano, durante o qual os(as) alunos(as) precisavam cumprir a totalidade do programa de conteúdos, constituído por 17 disciplinas, divididas em teóricas e práticas. Para tanto, as aulas ocorriam em turno integral e, por conta disso, não foram poucos os relatos de esgotamento vindos de ex-alunas. Para Maria de Lourdes Fonseca (2010), ter optado por obter a formação em Educação Física não lhe trouxe arrependimentos. Entretanto, recorda-se que, durante o período, emagrecera muito, "ora, perder 12 quilos em nove meses é um bocado, não é?” (FONSECA, 2010, p. 1).

As especificidades e os contornos que o Curso Normal de Educação Física da ESEF (1940-1956) adotou ao longo de sua trajetória foram possíveis de ser delineados ao adentrarmos em seus espaços físicos e simbólicos. As composições de seus saberes disciplinares, interpretados por meio das informações descritas nos programas de ensino e, também, através das práticas que permaneceram na lembrança de ex-alunas, nos permitiram traçar uma leitura, de acordo com os pressupostos teóricos de Chartier (2017), acerca da formação obtida no interior do Curso Normal. Diante disso, percorrendo o caminho delineado pelos vestígios apresentados à pesquisa, uma característica que se destacou foi a presença significativa de militares na conformação inicial da instituição.

$\mathrm{Na}$ demarcação de uma forma de funcionamento da ESEF, que a aproximava, em parte, daquela constituinte das instituições militares, docentes e direção empenhavam-se para dar conta do trabalho pedagógico de especializar professores(as) de Educação Física. Ao compor as estruturas diretivas e, principalmente de ensino, os militares figuraram ao lado dos médicos, na estrutura basilar da ESEF (GUTIERREZ, 1972; MAZO, 2005; LYRA, 2013). No depoimento da ex-aluna do Curso Normal, Anna Tereza Morais (2010), a presença expressiva de médicos e 
militares foi abonada. Ao discorrer acerca do período em que frequentara a instituição, no ano de 1941, Anna destacou que "na escola eram só militares no primeiro ano (MORAIS, 2010, p. 5)".

Recordemos que estudos no âmbito da História da Educação Física no Brasil enfatizam as influências de ambas as categorias mencionadas, na construção do campo da formação de professores(as) no país (MARINHO, 1953; 1956; CASTELLANI FILHO, 1988; GHIRALDELLI, 1992; MELO, 1996; SOARES, 1996; 2001; FERREIRA NETO, 1997; 1998; 1999; VAGO, 1999; MAZO, 2003; 2005). Além da presença de médicos e militares, é preciso reconhecer que a Escola Nacional de Educação Física e Desportos (ENEFD), também estabeleceu orientações que auxiliaram no estabelecimento de instituições superiores no país. ${ }^{1}$

A instituição sul-rio-grandense, para além de reproduzir algumas das práticas provindas da ENEFD, também abarcou em seu fluxo características formativas e disciplinares próprias (LYRA; MAZO, 2016). Talvez, guardadas as suas particularidades, uma das características que pode ter figurado de modo comum nos modelos de ensino das instituições superiores criadas entre as décadas de 1930 e 1940, foi o "padrão" estabelecido pela Escola de JoinvilleLe-Pont, de onde emergiu o Método Francês de Educação Física. Esse método foi oficializado, inicialmente, no Centro Militar de Educação Física que, no ano de 1933, transformou-se em Escola de Educação Física do Exército (ESEFEX). Foi no interior dessas organizações que se formaram instrutores militares e professores civis que, posteriormente, foram responsáveis pela criação das escolas superiores de formação profissional em Educação Física no país.

Neste panorama delineado em fins da década de 1930 e início da década de 1940, a ESEF, refletindo o movimento ocorrido nas demais instituições superiores criadas no Brasil, foi estabelecida enquanto uma escola civil de formação de professores(as) de Educação Física, sendo seus saberes disciplinares orientados por docentes com formação militar. Diante disso, conforme já nos acenava o professor Jacintho Targa, capitão da Brigada Militar, "como eles [os professores com orientações militares] haviam assimilado a doutrina francesa, é natural que os mesmos procurassem difundi-la" (TARGA, 1946 apud MARTINI et al., 2010, p. 59). Essa difusão estava explicitada nos próprios programas de ensino das disciplinas do Curso Normal da ESEF, uma vez que, eram os próprios professores que os elaboravam. Acerca desta questão, evidenciamos que o Decreto-Lei n. ${ }^{\circ}$ 1.212 de 1939, além de apresentar as bases do que podemos chamar 
de "primeiro currículo de nível superior destinado à formação de professores(as) deEducaçãoFísica noBrasil”" (CASTELLANI FILHO, 1999, p. 22-23), também previu orientações sobre a organização "Do Regime Escolar" (BRASIL, 1939, p. 4). Em seu Artigo 29, por exemplo, estava posto que "para cada disciplina haverá um programa que será elaborado pelo professor catedrático dela encarregado" (BRASIL, 1939, p. 5, grifo nosso). Ao encontro dessa orientação, no Regimento Interno do DEEF antevia-se um ato de fiscalização, para averiguação do cumprimento das informações e, especialmente, das sequências de aprendizado, postas nos programas de ensino. No Artigo $12^{\circ}$, parágrafo IX, descrevia-se:

À Seçãa $^{2}$ Didática, dirigida pelo respectivo adjunto, compete organizar e manter
em dia, em livros especiais, quadros demonstrativos da progressão das aulas
teóricas e práticas, com um mapa alterado diariamente, de maneira a poder
informar o Chefe da Divisão do adiantamento do ensino em determinada matéria,
para efeito de fiscalização do cumprimento dos programas (RIO GRANDE
DO SUL, 1943, p. 3 , grifos nossos).

As informações descritas acima, além de demonstrarem a presença de um caráter de controle do DEEF sobre as atividades desenvolvidas pelos(as) professores(as) na ESEF, também forneceram elementos que ratificaram a responsabilidade direta dos(as) docentes, no que concerne ao planejamento dos conteúdos a serem ministrados em suas disciplinas. Por conseguinte, nossos esforços foram orientados no sentido de reconhecer, em meio aos conteúdos de ensino, aquelas orientações dotadas de um caráter militarizado e que arquitetaram, de modo objetivo, a influência militar e, consequentemente, a presença de práticas advindas do Método Francês.

Nesse caminho, o delineamento das similaridades pôde ser demarcado na própria organização estrutural dos programas de ensino de determinadas disciplinas. Conforme nos aponta Marinho (1953), a primeira parte do Método Francês subdividia-se em elementar, secundária, superior e feminina. Essa mesma disposição conformou os conteúdos da disciplina de Educação Física Geral - Feminina, onde se solicitava a realização de sessões de ginástica específicas a cada um desses ciclos mencionados (PROGRAMA DE ENSINO DE EDUCAÇÃO FÍSICA GERAL - FEMININA, 1940).

Provavelmente, tal aproximação tenha se dado em razão de o primeiro professor catedrático desta disciplina ser o tenente João Gomes Moreira Filho. Além de atuar enquanto professor da ESEF, o tenente também desempenhava suas funções junto à Brigada Militar de Porto Alegre/RS e havia obtido sua formação na ESEFEX, fato este 
que ratifica a influência desta instituição na difusão de conhecimentos relacionados ao Método Francês. No que concerne aos conteúdos programáticos do saber disciplinar acima mencionado, demarcamos a presença de "evoluções a pé firme", bem como de "marchas", sendo esta última subdivida em "evoluções em marcha" e "exercícios de ordem".

De modo mais explícito, o Método Francês foi apresentado como referência para elaboração dos conteúdos programáticos do saber disciplinar de Desportos de Ataque e Defesa. Dentre as práticas evidenciadas, destacamos o box inglês, o jüu-jitsu e a luta grecoromana, uma vez que estas aparecem listadas tanto no programa de ensino da disciplina como no material referente ao Método Francês (PROGRAMA DE ENSINO DE DESPORTOS DE ATAQUE E DEFESA, 1940; MARINHO, 1953). O professor responsável pelos ensinamentos deste saber disciplinar era o sargento Waldir Calvet Echart que, assim como o tenente João Gomes Moreira Filho, também atuava junto à Brigada Militar de Porto Alegre/RS e fora cedido para trabalhar na ESEF. Antes disso, todavia, frequentou a ENEFD, no Rio de Janeiro (BEGOSSI, 2017).

No depoimento da ex-aluna e ex-professora da ESEF, Olga Kroeff Echart, esposa de Waldir Echart, evidencia-se que "a maioria dos professores de Educação Física do Rio Grande do Sul, naquela época, eram militares". Segundo Olga, "eles eram mandados a tirar o curso de Educação Física no Rio [Rio de Janeiro/RJ]", mencionando ainda que "foram poucos os professores "leigos" que atuaram na ESEF" (ECHART, 2004, p. 8). Possivelmente, os "professores leigos" a que Olga Kroeff Echart se refere sejam os(as) docentes não militares, que obtiveram suas formações junto às escolas superiores civis de Educação Física.

A presença do Método Francês enquanto guia das disciplinas do Curso Normal de Educação Física da ESEF foi recorrente na memória de ex-alunas. Para Quintina Paccini, ex-aluna e também ex-professora da instituição, os direcionamentos dos conteúdos advinham do referido método. Quintina (2005, p. 4) afirmou: "era só Método Francês. Nós recebemos da Escola esse Método e tudo girava em torno dele. [...] Quando nós começamos a trabalhar, as aulas eram orientadas por este Método". De modo similar, a ex-aluna Ilse Engel Guterres, menciona que "na época (1941) era a Escola Francesa que se seguia. Praticamente todas as matérias eram ligadas à Ginástica Francesa” (GUTERRES, 2004, p. 6).

Ao encontro das ponderações delineadas, evidenciamos o estudo de Ferreira Neto (1997), intitulado "Projeto Militar na Educação 
Física" que, de modo significativo, traça evidências acerca da aplicação do Método Francês no ensino da Educação Física. Ferreira Neto (1997) destaca que a transmissão de conteúdos relacionados com a Educação Física, quando orientada por um viés militar, ou seja, embasada pelo Método Francês, se dava por meio de sessões, compreendidas enquanto a execução (prática) dos exercícios escolhidos. Além disso, "o processo de ensino das lições de Educação Física exigia do instrutor exposição oral e demonstração minuciosa e, da classe, imitação precisa” (FERREIRA NETO, 1997, p. 114 - grifos nossos).

O termo "sessões" foi significativamente recorrente na escrita dos conteúdos programáticos dos saberes disciplinares do Curso Normal de Educação Física. Assim sendo, localizamos o referido termo nos programas de ensino de Cinesiologia, Desportos de Ataque e Defesa, Desportos Terrestres Coletivos (Futebol e Volibo), Desportos Terrestres Individuais (Corridas, Ginástica de aparelhos e levantamento de pesos e halteres, e Saltos), Educação Física Geral - Feminina, Ginástica Rítmica e Metodologia da Educação Física. Nesses programas, conforme foi possível observar, a nomenclatura "sessão" referia-se às aulas propriamente ditas.

De outro modo, o termo "instrutor", evidenciado por Ferreira Neto (1997) nos possibilitou refletir acerca da própria representação de identidade do professor de Educação Física do período. Para tanto, consultamos o documento produzido por Inezil Penna Marinho, intitulado "Coletânea de aulas do Curso de Aperfeiçoamento para professores de Educação Física", datado de 1952. Nesse material, o professor Inezil apresenta, em um dos tópicos, o traçado de uma plausível evolução da formação do professor de Educação Física no Brasil, destacando, no Artigo 451' , o seguinte:

A título provisório, enquanto não puderem ser substituídos pelos professores diplomados pela Escola Profissional de Educação Física serão para os grupos escolares e escolas fundamentais e profissionais contratados instrutores de educação física (MARINHO, 1952, p. 2 - grifo nosso).

Diante disso, podemos conjecturar que até que fossem formados os primeiros professores de Educação Física, em cursos específicos da área, os "instrutores" é que assumiriam o trabalho com a Educação Física em instituições de ensino. Um pouco mais adiante no documento construído por Marinho (1952), essa questão é retomada e fornece novos indícios às nossas considerações. Ao tratar da "Evolução do conceito do professor de Educação Física - ação educativa e ascendência do professor", o autor descreve: "Outrora 
o professor de educação física denominava-se instrutor de cultura física. Não havia ainda a preocupação de educar fisicamente, mas tão só a de cultivar o físico, isto é, desenvolver os músculos" (MARINHO, 1952, p. 3 - grifos nossos).

O autor (1952, p. 3) ainda destaca, que "o professor de hoje [1952] impõem-se pela dose de conhecimentos científicos de que está dotado". Os trechos citados demonstram que a construção de uma identidade, a partir da obtenção de conhecimentos científicos, via formação profissional específica, diferia o antes "instrutor" do então "professor de educação física". Este deveria superar a experiência empírica e prática e alocar seu ensino em conhecimentos científicos, a fim de "educar fisicamente" seus alunos.

Apesar disso, Marinho (1952, p. 3) reconhece que ainda durante aquele contexto perdurava o conceito "errôneo" de que o professor de Educação Física deveria ser também um atleta. Para ele, "as suas performances [as do professor] são sempre comparadas às dos campeões nesta ou naquela especialidade. Nada mais falso, nada mais absurdo". Diante disso, enquanto Marinho (1952) reflete acerca do "professor-atleta", Ferreira Neto (1997) nos traz o termo "demonstração minuciosa", ambos referindo-se às condições físicas e/ou técnicas exigidas ao professor, para o trabalho com a Educação Física.

Essa característica também existiu nos programas de ensino do Curso Normal da ESEF. Para a disciplina de Educação Física Geral - Feminina, a orientação de que o professor deveria ser um exímio executante de suas lições, estava posta no terceiro objetivo da disciplina. Nele descrevia-se: "Dar-lhes o treinamento físico indispensável para que sejam bons executantes dos exercícios que irão ministrar" (PROGRAMA DE ENSINO DE EDUCAÇÃO FÍSICA GERAL FEMININA, 1940, p. 1 - grifo nosso). Para a disciplina de Metodologia da Educação Física, essa característica aparecia de modo tímido, na subdivisão de conteúdos, vinculada ao eixo referente, justamente, ao Método Francês de Educação Física. Nessa parte estava posta a seguinte relação de temáticas a serem estudadas:

\footnotetext{
Regras para a conduta, direção e execução do trabalho físico - Qualidades do professor de Educação Física; Apresentação pessoal; Qualidades pessoais; Preparação intelectual e material da sessão de trabalho; Direção da sessão; Comandos; Disposição dos alunos e colocação do professor e do guia; Indicação de ritmo; Correção dos erros [...] (PROGRAMA DE ENSINO DE METODOLOGIA DA EDUCAÇÃO FÍSICA, 1940, p. 1 - grifos nossos).
}

Embora apresentadas de formas distintas, tanto no programa de ensino da disciplina de Educação Física Geral - Feminina, como no 
documento pedagógico de Metodologia da Educação Física, figurava a ideia de que o professor de Educação Física deveria, para além de manter a conduta, direção e ordem de suas aulas, ser dotado de qualidades que lhe permitissem demonstrar à classe, os movimentos solicitados. Além disso, conforme destacado no fragmento acima, o professor deveria se colocar em um ponto de comum visão a toda classe e corrigir erros que porventura ocorressem. Esses aspectos, igualmente, figuravam dentre as prescrições instituídas pelo Método Francês, o que, de alguma forma, estabelece similaridades entre as práticas do Curso Normal e as orientações do referido Método (MARINHO, 1953).

A partir dos vestígios apresentados pelos documentos consultados, os fios nos conduzem a tecer uma trama, onde a formação ocorrida no Curso Normal da ESEF confundia-se, por vezes, com as práticas oriundas das instituições militares. Essa influência de preceitos militares se tornou ainda mais manifesta no depoimento da ex-aluna Zilca Rossi Montanari (2011), quando relata a organização dos tempos dentro da ESEF:

De início, de manhã, tinham as aulas práticas. Sete e meia, o Tenente Moreira, a lá moda de soldado ia pro meio do campo e soava o apito. A turma toda lá, em ordem, cumprindo com seus monitores. Ali, então, trazia uma tabela com o que nós íamos receber. Se era Educação Física Geral, se era Atletismo, se era Jogo, cada horário estava ali. Eram três aulas. Sete e meia em ponto começava, até as dez e pouco. Nesse tempo tínhamos três aulas práticas. Após, tinha um pequeno recreio. Depois, íamos lá para o pavilhão, onde tinha duas aulas teóricas. Também lá, de acordo com a tabela nós víamos se hoje é cinesiologia, amanhã anatomia, história... Nós íamos lá naquele quadro, exposto logo na entrada para ver o que nós tínhamos no dia. Se nós tivéssemos, por exemplo, Ginástica Rítmica, tinha que estar com o uniforme de Ginástica Rítmica. Até semanalmente tinha lá, a previsão do trabalho (MONTANARI, 2011, p. 8, grifos nossos).

O trecho do depoimento nos fornece subsídios relevantes para pensarmos que, não era apenas nos saberes disciplinares que o caráter militar figurava. Ele se fazia presente na organização dos tempos, nas orientações de posturas a serem adotadas pelos(as) alunos(as), no uso de uniformes e, de modo explícito, na lembrança dos sujeitos que vivenciaram o ambiente de formação. O caráter militar, portanto, perpassou as práticas de ensino da ESEF de modo amplo e, de modo particular, da própria formação ocorrida no Curso Normal.

Todavia, para além das condutas rígidas e do aprendizado de saberes disciplinares orientadores, que pareciam querer legitimar a adoção do Método Francês no ambiente educacional da instituição, os documentos de pesquisa apresentaram sinais da presença de outro movimento, ainda que incipiente. Este se referia à projeção de 
métodos, sistemas ou mesmo de formas de ensino distintas daquela que, de modo oficial, figurava no contexto delineado. Guardadas suas particularidades, o que se observou nos aparatos pedagógicos interpretados foi o comparecimento de saberes que visavam a preparação dos(as) professores(as) para atuação com a Educação Física no ambiente educacional. Essa temática é tratada no tópico que segue.

\section{O CARÁTER PEDAGÓGICO NOS SABERES DISCIPLINARES}

O Curso Normal de Educação Física da ESEF, tendo por desígnio maior a preparação do professorado sul-rio-grandense para atuação nas escolas estaduais, pareceu imprimir a seus programas de ensino práticas de formação portadoras também de um caráter pedagógico. Essas figuravam ao lado dos conteúdos interpretados por nós, como possuidores de um caráter militarizado, os quais avocavam para si a legitimidade assinalada pelo Método Francês. Mesmo que tenha sido possível traçarmos aproximações entre a instrução ocorrida no Curso Normal da ESEF e o referido método, foi preciso refletir, igualmente, acerca das críticas que tal viés de ensino recebera na época.

Antes mesmo de o Método Francês ser oficializado no Brasil do ponto de vista da legislação, a Associação Brasileira de Educação (ABE) já havia se posicionado contrária a sua adoção. Dentre os argumentos que justificavam esse posicionamento, estava a não aceitação de levar à escola uma educação de viés militar. No fragmento abaixo, trazido da obra de Marinho (1953) é possível observar qual era o princípio que orientava a Educação Física, no meio educacional brasileiro da época, do ponto de vista da ABE:

[...] à luz das doutrinas modernas da pedagogia, o princípio imutável da educação física reside na preocupação de assegurar o desenvolvimento físico em harmonia com o desenvolvimento intelectual e moral. Separá-los é um êrro pedagógico. A educação intelectual, a educação física, a educação moral, estão ligadas intimamente entre si e visam o objetivo comum de desenvolver a personalidade, o caráter, a inteligência da criança, a aptidão, em suma, para como indivíduo, viver, trabalhar, produzir e tornar-se, na coletividade, um agente social eficiente (MARINHO, 1953, p. 167, grifos nossos).

Conforme podemos observar no inserto destacado acima, o "desenvolvimento físico" deveria ser desenvolvido juntamente às dimensões intelectual e moral da criança. Percebe-se certa ampliação da compreensão do que a disciplina de Educação Física deveria representar nos moldes educacionais do período, devendo superar o conceito que tinha por fim a educação para e pela prática. Acerca 
desta questão, assinalamos que a tríade educação "física, intelectual e moral" já figurava nos debates educacionais, ao menos no ponto de vista legal, enquanto conteúdo a ser desenvolvido durante a formação obtida nos Cursos Complementares, ${ }^{3}$ no ano de 1909 (RIO GRANDE DO SUL, 1909).

O termo "educação physica", descrito desta maneira por conta da grafia da época, emergiu no programa da formação de professores(as) do Curso Complementar do estado do Rio Grande do Sul, ao lado dos saberes de educação intelectual e moral. Tais ensinos eram partes da disciplina de Pedagogia, a qual abarcava também questões relacionadas às "noções de hygiene" e a "Gymnastica sueca" (BEGOSSI, 2017). De modo semelhante, Vago (1997, p. 35) em seu estudo acerca da escolarização da Gymnastica nas Escolas Normais de Minas Gerais (1883-1918), ratificou a presença de uma educação "physica" integrante de uma "tríade" que, também, articulava uma educação "intellectual” e moral.

Neste caminho, o que os materiais de pesquisa nos demonstraram é que a educação do corpo vinha sendo reinterpretada em sua função formadora, desde o período em que a Educação Física figurava enquanto um conteúdo de ensino, no interior de uma matéria, nas grades de horários dos cursos de formação de professores(as) primários(as) do estado. Os (novos) contornos que foram sendo assumidos com o passar do tempo, solicitavam a articulação de preceitos morais, juntamente a valores intelectuais, os quais preparariam os(as) futuros(as) professores(as) para atuação nas escolas primárias do período. Aliado a essa questão, estava o posicionamento da "educação physica" no interior da matéria de Pedagogia, o que a fez assumir de certa forma, um enfoque pedagógico. Ademais, destacava-se a presença de conteúdos ligados à "Gymnastica Sueca”, possivelmente incluída no rol dos conteúdos de Pedagogia em razão de seu caráter educativo e de sua amplitude de direcionamentos.

Desse modo, se nas bases da formação do professorado do estado do Rio Grande do Sul os conteúdos pedagógicos interligavam-se à importância de desenvolver uma educação do corpo, a permanência deste caráter em um curso específico de formação de professores(as) de Educação Física era praticamente inevitável, em virtude dos reflexos que ainda circulavam no campo. Os apontamentos foram presumíveis de serem demarcados ao consultarmos os programas de ensino de determinados saberes disciplinares, orientadores da formação ocorrida no interior do Curso Normal da ESEF. Nessa direção, a partir de um olhar mais atento aos materiais constituintes 
do estudo, localizarmos indícios que aproximavam os conteúdos ensinados no Curso Normal, dos princípios defendidos pela ABE. Tais aspectos, do ponto de vista prático, constituíam-se em orientações direcionadas, especialmente, ao trabalho pedagógico empreendido nas escolas e voltado à educação física infantil ou, conforme denominado na época, ao ciclo elementar. Esses direcionamentos foram apontados nos objetivos de alguns saberes disciplinares e, por vezes, na própria descrição dos eixos de conteúdos.

$\mathrm{Na}$ disciplina de Biometria, a atenção a ser dada ao ensino nas escolas estava posto logo no primeiro objetivo, a saber, "Ministrar conhecimento de Biometria Humana e em especial da parte que se aplica ao ciclo elementar". Esta pretensão é reforçada no eixo nove de conteúdos, o qual se refere ao "Estudo biométrico do crescimento", destacando-se a "aplicação destes conhecimentos à Educação Física Infantil” (PROGRAMA DE ENSINO DE BIOMETRIA, 1940, p. 1, grifos nossos). De modo pontual, o saber disciplinar de biometria buscava dotar os(as) alunos(as) do Curso Normal com ferramentas que os(as) possibilitassem compreender e avaliar o desenvolvimento das crianças do ponto de vista físico.

De modo semelhante, para a disciplina de Cinesiologia, o direcionamento de conteúdos ao "ciclo elementar" foi manifesto em seu objetivo, a saber: "Fornecer elementos suficientes que permitam contribuir para a profilaxia e tratamento de alguns defeitos físicos e atitudes defeituosas incipientes, muito comuns em alunos do ciclo elementar". No eixo cinco do referido saber disciplinar, apresentavamse também "noções sobre as causas mais comuns dos "defeitos físicos" e "atitudes defeituosas" entre os escolares" (PROGRAMA DE ENSINO DE CINESIOLOGIA, 1940, p.1). Ao que nos parece, apesar de os preceitos orientadores intentarem articular uma educação que superasse somente o ponto de vista físico, percebemos que determinados conteúdos de ensino do Curso Normal da ESEF pareciam querer reforçar essa questão.

Essetraçado, todavia, podesercompreendidoaoposicionarmos o médico capitão Ruy Gaspar Martins enquanto docente responsável pela disciplina, nos primeiros anos de funcionamento da ESEF. Enquanto militar e médico, provavelmente o professor primasse pela melhoria da aptidão física e pelo desenvolvimento de boas condições corporais desde a infância. Aliás, recordemos que os(as) próprios(as) candidatos(as) ao ingresso no Curso Normal da ESEF eram avaliados em provas práticas, sendo submetidos a uma triagem realizada por médicos e militares, acerca de suas condições de saúde. $\mathrm{O}$ aceite ou 
não de suas matrículas, portanto, estava dependente dos julgamentos iniciais (MAZO, 2005; LYRA, 2013; BEGOSSI, 2017).

Ao retomar a busca pela presença de aspectos pedagógicos elencados nos saberes disciplinares do Curso Normal, destacamos a disciplina de Desportos Terrestres Coletivos, especialmente, os programas de ensino de basquetebol e volibol. Nos documentos, expressava-se, já nos objetivos, a intenção de dar aos(às) alunos(as) "a capacidade pedagógica necessária para ministrar o ensino do basquetebol (e do volibol) no meio infantil, com finalidade educativa e recreativa" (PROGRAMA DE ENSINO DE DESPORTOS TERRESTRES COLETIVOS, 1940, p. 1; 3, grifos nossos). O termo "capacidade pedagógica" também se fez presente no programa de ensino de Educação Física Geral - Feminina, ao ressaltar que o aprendizado dos conteúdos da referida disciplina deveria "proporcionar aos alunos a capacidade técnica e pedagógica para ministrar e dirigir a Educação Física em estabelecimentos de ensino secundário" (PROGRAMA DE ENSINO DE EDUCAÇÃO FÍSICA GERAL - FEMININA, 1940, p. 1, grifo nosso).

O saber disciplinar de Educação Física Geral - Feminina apresentou significativas aproximações com o caráter pedagógico de ensino, especialmente, através de orientações destinadas à educação infantil. O segundo objetivo deste saber, por exemplo, mencionava a importância do aprendizado da execução correta dos exercícios destinados ao "ciclo elementar". Talvez, este destaque tenha sido feito em razão de os movimentos básicos servirem de alicerce ao aprendizado de sequências de exercícios mais complexas, advindas nas fases posteriores. Este ponto foi reforçado ao localizarmos, em um dos eixos de conteúdos postos no programa da disciplina, a orientação de se prever "sessões de ginástica específicas a cada um dos ciclos escolares", dando a compreensão de que havia certa progressão no aprendizado (PROGRAMA DE ENSINO DE EDUCAÇÃO FÍSICA GERAL - FEMININA, 1940, p. 1).

Ainda acerca do programa de ensino do saber de Educação Física Geral - Feminina, alguns aspectos alocados nos seus eixos de conteúdos nos chamaram a atenção. Além das "evoluções a pé firme" e da "marcha", que se vinculam a conteúdos portadores de um caráter militarizado, podemos elencar a presença de aulas que objetivavam desenvolver o ensino de "grandes e pequenos jogos", da "calistenia para crianças" e da "ginástica sueca" (PROGRAMA DE ENSINO DE EDUCAÇÃO FISICA GERAL - FEMININA, 1940, p. 1-2). De modo similar, o programa de ensino do saber de 
Metodologia da Educação Física, por meio de um eixo de conteúdos denominado "Educação Física Escolar", também elencava a "calistenia nas escolas primárias" e o "jogo infantil", como conteúdos de ensino (PROGRAMA DE ENSINO DE METODOLOGIA DA EDUCAÇÃO FÍSICA, 1940, p. 3).

Os exercícios calistênicos eram possuidores de um significativo valor pedagógico. Por conta disso, eram vistos pelo Professor Frederico Guilherme Gaelzer ${ }^{4}$ como possibilidade de conteúdo a ser desenvolvido nas escolas, durante as aulas de Educação Física. Destacamos que o professor Gaelzer foi um dos precursores da Educação Física no estado, além de ter auxiliado na estruturação das bases do que viria a se tornar a ESEF, no ano de 1940. Tendo estreita ligação com as Associações Cristãs de Moços (ACM's), onde a Ginástica Sueca e, sobretudo, o Método Calistênico foi difundido, construiu sua carreira em países como a Alemanha, Suécia, Estados Unidos, México e Uruguai. Ao retornar ao Brasil, no ano de 1925, trouxe consigo novas formas de pensar a Educação Física, bem como seus métodos de ensino. Possivelmente, suas ideias com relação à formação de professores(as) de Educação Física se refletiram em sua prática enquanto docente da ESEF e orientaram sua atuação também enquanto diretor da instituição, no período de 1955 a 1959.

Desse modo, podemos presumir que os(as) docentes que se responsabilizaram pelo ensino dos conteúdos nos anos iniciais de atividade da ESEF, imprimiram à prática profissional características e conhecimentos advindos de suas próprias experiências. Nesse caminho, mencionamos a presença de indícios que assinalam a existência, mesmo que de maneira menos explícita, de orientações advindas do Método Alemão. $\mathrm{Na}$ busca por localizar pistas de características, nos deparamos com o nome do professor Karl Black, ${ }^{5}$ como um dos primeiros responsáveis pelas aulas de Ginástica de aparelhos e levantamentos de pesos e halteres.

Os vestígios mencionados localizavam-se na descrição da bibliografia utilizada pelo docente para elaboração do programa de ensino da referida disciplina. Nesta parte, das nove referências descritas, sete estavam no idioma alemão. ${ }^{6}$ O professor Karl Black, além de ser frequentador da primeira sociedade de ginástica criada pelos teuto-brasileiros no estado do Rio Grande do Sul, a "Turnerbund" (atual Sociedade de Ginástica Porto Alegre, 1867, conhecida pela sigla SOGIPA), também obtivera sua formação na Alemanha. Diante dos indicativos, é possível presumir que, possivelmente, a inclusão de conteúdos que remetem ao Método Alemão, nas práticas de ensino 
da ESEF, tenha sido resultado de saberes experienciais trazidos pelo professor Karl Black, em razão da vivência com o mencionado método, em distintos ambientes.

Seguindo no percurso por delinear o caráter pedagógico nos programas de ensino dos saberes disciplinares do Curso Normal da ESEF, localizamos nos conteúdos de Canto Coral, a orientação de que o "Ritmo" deveria ser "base da disciplina e principal elemento da educação coletiva das escolas [...]" (PROGRAMA DE ENSINO DE CANTO CORAL, 1940, p. 1, grifo nosso). De modo similar, a disciplina de Ritmo previa, em seu documento de orientação, o ensino às alunas "dos meios práticos para desenvolver na criança o senso natural do ritmo" (PROGRAMA DE ENSINO DE RITMO, 1940, p. 1, grifo nosso). Dessa forma, ao colocar a criança enquanto receptora dos conhecimentos aprendidos e a educação coletiva das escolas enquanto local de ensino, se sobressaem, em ambos os saberes, aspectos de ordem pedagógica, os quais visavam desenvolver, nos escolares, noções de ritmo que contribuiriam para com a formação integral.

Nessa mesma direção, as crianças também são apresentadas enquanto receptoras de um saber a ser repassado, nos objetivos da disciplina de Ginástica Rítmica. A segunda principal finalidade desse saber era "dar às alunas conhecimentos necessários para dirigir sessões de ginástica rítmica para o Ciclo Secundário e Superior". O terceiro desígnio previa a "capacitação das alunas para adaptar os exercícios de ginástica rítmica para crianças "sobre" [sob] a forma de historietas musicadas" (PROGRAMA DE ENSINO DE GINÁSTICA RÍTMICA, 1940, p.1, grifo nosso). Para além das finalidades explicitadas nos objetivos, previa-se, ainda, certa contribuição para a formação psíquica da criança e, sobretudo, o ensino das atividades rítmicas em um plano educacional geral.

Diante disso, tornou-se notório, por meio dos indícios apresentados pelos documentos consultados, que a preocupação com o processo educacional e formativo, especialmente das crianças, se fez presente nos saberes disciplinares do Curso Normal da ESEF. Tais aspectos sustentam, em certa medida, nossas reflexões iniciais acerca da manifestação de alicerces pedagógicos nas bases da formação de professores(as) ocorrida na ESEF. Essas características de ensino, conforme evidenciamos, figuraram ao lado de princípios militares, os quais se ligavam, especialmente, a aplicação do Método Francês.

Situação semelhante foi ratificada por Ferreira Neto (1999) ao analisar os planos curriculares e de ensino da Escola de Educação Física do Exército e da Escola de Educação Física do Espírito Santo. Segundo 
o autor (1999, p. 149), é possível afirmar que "a ênfase na formação do professor de Educação Física, já na década de 1930, era posta em seu caráter pedagógico". Todavia, Ferreira Neto (1999) não exclui as influências de fundamentos biológicos e militares nesses cursos. Apenas evidencia, por meio da leitura a esses cenários, que os reflexos apareciam em menor proporção nessas instituições de ensino.

$\mathrm{Na}$ Escola sul-rio-grandense, o Curso Normal de Educação Física entrou em funcionamento sendo norteado, sobretudo, pela necessidade de formar professores(as) para atuar junto às escolas de ensino fundamental do estado. Recordemos que, após a promulgação da Constituição de 1937, a qual tornou a Educação Física disciplina obrigatória nos estabelecimentos de ensino do país, o contexto educacional precisou moldar-se a esse (novo) campo de atuação e, portanto, passou a impulsionar a criação de escolas civis de formação profissional. Nota-se que a demanda por docentes especializados foi estabelecida antes mesmo da existência de uma formação específica na área (BEGOSSI, 2017).

A presença de conteúdos pedagógicos nos programas de ensino do Curso Normal de Educação Física pode ser compreendida como meio de preenchimento de uma necessidade de saberes já instituída, pelas condições nas quais o campo foi conformado. Ora, se os(as) profissionais formados(as) no Curso Normal seriam direcionados para as escolas estaduais, nada mais coerente do que ensiná-los a utilizar, de modo apropriado, ferramentas pedagógicas.

\section{CONSIDERAÇ̃̃ES FINAIS}

Neste estudo, buscamos compreender as composições dos saberes disciplinares que orientaram a formação no Curso Normal, da Escola Superior de Educação Física (ESEF), do estado do Rio Grande do Sul (1940-1956). Nesse caminho, identificamos, nos documentos de orientação pedagógica do curso, influências que circundavam o campo e que traduziam ao ambiente de ensino, determinadas orientações. À primeira vista, foi possível demarcarmos a existência de um caráter militarizado, o qual era expresso, principalmente, através da presença de saberes relativos ao Método Francês. Esse aspecto, corroborava com as características expressas por outras instituições formadoras de professores(as) de Educação Física, criadas no mesmo contexto.

A presença do viés militarista na ESEF e, de modo pontual, no Curso Normal, figurou de forma significativa nos programas de ensino do referido curso e, também, na memória de ex-alunas 
e ex-professoras da instituição. Nesse sentido, os documentos orais eleitos ao estudo, nos permitiram ter acesso aos acontecimentos históricos, através das representações formuladas por sujeitos que testemunharam o período investigado. Os discursos adotados para a feitura da presente narrativa operaram enquanto canais de acesso ao passado, possibilitando o reconhecimento da maneira como os atores sociais deram sentido a suas práticas.

Para além, demarcamos que o Método Francês foi ladeado na instituição sul-rio-grandense pela emergência de novas formas de se pensar e se fazer Educação Física. Nessa direção, pontuamos a presença de um caráter pedagógico no interior dos programas de ensino do Curso Normal. Este aspecto apresentou-se à nossa pesquisa, inicialmente, como um fragmento, situado dentre os ensinos que detinham certa hegemonia no campo. De modo específico, ao localizarmos, em meio aos aspectos do Método Francês, questões que remetiam à presença também de atributos pedagógicos, a escrita da presente narrativa foi reconduzida, buscando centrar as interpretações também nessas informações, as quais, em um primeiro momento foram consideradas marginais, mas, que, posteriormente, se tornaram reveladoras.

Da mesma forma que Ginzburg (1989) evidenciou em seu estudo a necessidade de se "examinar os pormenores mais negligenciáveis", os registros acerca da presença de conteúdos pedagógicos nos programas de ensino foram possíveis de ser acessados através da busca pelo que não estava explícito no princípio. Os aspectos pedagógicos foram expressos nos programas de ensino dos saberes disciplinares do Curso Normal, envolvendo distintos sistemas, métodos e práticas de ensino, as quais coexistiram no ambiente de formação. Os conteúdos aprendidos pelos(as) professores(as) passariam a ser ensinados às crianças nas escolas primárias da época, sendo carregados de preceitos de um tempo em que a Educação Física buscava se estabelecer enquanto campo de formação e, nesse mesmo caminho, demarcar seus limites disciplinares e modos de ensino. Todavia, o que se tornou manifesto foi que, durante o período estudado (1940-1956), o processo histórico de construção de uma identidade própria estava apenas se iniciando.

A partir desses apontamentos, distinguimos que a pretensão deste estudo não foi localizar uma lógica entre os dispositivos interpretados para se construir uma narrativa historiográfica uniforme. De outra forma, nossos esforços foram projetados no sentido de se compreender, mesmo que de modo parcial e lacunar como nos diz Michel de Certeau (2017), as composições da arquitetura disciplinar 
do Curso Normal da ESEF. Diante disso, a realização deste estudo se justifica pela possibilidade de produzir, para além de um discurso, também um conhecimento sobre o passado, especialmente almejando contribuir para a História da Educação Física brasileira.

\section{REFERÊNCIAS}

ALBERTI, V. Manual de História Oral. Rio de Janeiro: Editora FGV, 2005.

BACELLAR, C. Fontes documentais: uso e mau uso dos arquivos. In: PINSKI, C. (Org.). Fontes históricas. $2^{\mathrm{a}}$ Ed. São Paulo: Contexto, 2010, p. 23-80.

BEGOSSI, T. D. A construção dos Saberes Disciplinares do Curso Normal da Escola Superior de Educação Física do estado do Rio Grande do Sul. 2017. 187f. Dissertação (Mestrado). Universidade Federal do Rio Grande do Sul, Escola de Educação Física, Fisioterapia e Dança, Porto Alegre, RS.

BRASIL. Decreto n. 1212 de 17 de abril de 1939. Dispões sobre a criação da Escola Nacional de Educação Física e Desportos. Diário Oficial da União, Rio de Janeiro, seção 1, p. 49, 17 abr. 1939. Disponível em: <http://www2.camara.leg.br/legin/fed/declei/1930-1939/ decreto-lei-1212-17-abril-1939-349332-norma-pe.html>. Acesso em: 2018.

CASTELLANi FILHO, L. A Educação Física no Sistema Educacional Brasileiro: percurso, paradoxos e perspectivas. 1999. 185f. Tese (Doutorado) - Faculdade de Educação, Universidade Estadual de Campinas, Campinas.

CASTELLANI FILHO, L. Educação Física no Brasil: A história que não se conta. Campinas: Papirus, 1988.

CERTEAU, M. A escrita da História (tradução Maria de Lourdes Menezes). Rio de Janeiro: Forense, 2017.

CHARTIER, R. "Escutar os mortos com os olhos". Revista Estudos Avançados, São Paulo, v. 24, n. 69, p. 6-30, 2010.

CHARTIER, R. A história ou a leitura do tempo. $2^{\text {a }}$ Ed. $3^{\text {a }}$ Reimp. Belo Horizonte: Autêntica Editora, 2017.

CHARTIER, R. A nova história cultural existe? In: PESAVENTO, S. História e linguagens. Rio de Janeiro: Letras, p. 35. 2006.

DESBIENS, J. F. Mutações dos contextos socioeducativo e socioprofissional e desenvolvimento dos saberes profissionais no ensino da Educação Física. In: BORGES, C.; DESBIENS, J. F. (Orgs.). Saber, formar e intervir para uma Educação Física em mudança. São Paulo: Autores Associados, 2005, p. 83-110.

ECHART, O. K. Olga Echart. (depoimento, 2004). Porto Alegre: Centro de Memória do Esporte - ESEFID/UFRGS, 2005. Disponível em: <http://www.lume.ufrgs.br/ handle/10183/50000>. Acesso em: 2018.

FERREIRA NETO, A. A pedagogia do exército e na escola: a Educação Física brasileira (1880-1950). Espírito Santo: Facha, 1999. 
FERREIRA NETO, A. Escola de Educação Física do Exército (1920-1945): Origem e Projeto Político-Pedagógico. In: FERREIRA NETO, A. (Org.). Pesquisa Histórica na Educação Física. Vol. 3. Espírito Santo: Faculdade de Ciências Humanas de Aracruz, 1998. p. 69-95.

FERREIRA NETO, A. Projeto Militar na Educação Física. In: FERREIRA NETO, A. (Org.). Pesquisa Histórica na Educação Física. Vol. 2. Vitória: UFES. Centro de Educação Física e Desportos, 1997. p. 83-119.

FONSECA, M. L. Maria de Lourdes Fonseca. (depoimento, 2010). Porto Alegre: Entrevista para a tese de doutorado intitulada "A criação da Escola Superior de Educação Física no Rio Grande do Sul: Formação de professoras(es) para a construção do campo (1940-1970)".

GHIRALDELli Jr., P. Educação Física Progressista: A Pedagogia Crítico-Social dos Conteúdos e a Educação Física Brasileira. $4^{\text {a }}$ Ed. São Paulo: Edições Loyola, 1992.

GINZBURG, C. Mitos, emblemas, sinais: morfologia e história. Tradução Federico Carotti. São Paulo: Companhia das Letras, 1989.

GUTERRES, I. E. Ilse Engel Guterres (depoimento, 2004). Porto Alegre: Centro de Memória do Esporte - ESEFID/UFRGS, 2004. Disponível em: <http://www.lume.ufrgs. br/handle/10183/50017>. Acesso em: 2018.

GUTIERREZ, W. Histórico da Escola Superior de Educação Física da Universidade Federal do Rio Grande do Sul. 6 maio 1972. Disponível em: < http://www.lume.ufrgs.br/ bitstream/handle/123456789/471/RV00177.pdf>. Acesso em: 2018. Folheto explicativo em homenagem à ESEF pela passagem do seu $32^{\circ}$ aniversário.

LYRA, V. B. A Criação da Escola Superior de Educação Física do Rio Grande do Sul: Formação de professoras(es) para a construção do campo (1940-1970). 2013. 265f. Tese (Doutorado), Escola de Educação Física - Universidade Federal do Rio Grande do Sul, Porto Alegre.

LYRA, V. B.; MAZO, J. Z. Escola Superior de Educação Física do Rio Grande do Sul: De um modelo nacional ao protagonismo de um modelo estadual. Revista Educação e Fronteiras, Dourados/MG, v. 6, n. 18, p. 40-52, set./dez. 2016.

MARINHO, I. P. Coletânea de aulas no Curso de Aperfeiçoamento para professores de Educação Física. 1952. 79p.

MARINHO, I. P. História Geral da Educação Física. São Paulo: Cia Brasil Editora, 1956.

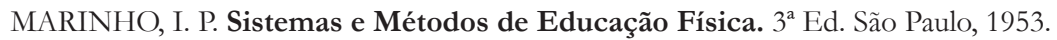

MARTINI S.; MAZO, J. Z.; LYRA, V. B.; SILVA, A. F. L. da. A Fundação da Associação dos Profissionais de Educação Física do Rio Grande do Sul - APEF/RS: recortes do cotidiano. Novo Hamburgo: Feevale, 2010.

MAZO, J. Z. A emergência e a Expansão do Associativismo Desportivo em Porto Alegre (1867-1945): espaço de representações da identidade cultural brasileira. 2003. $376 f$. Tese (Doutorado) - Curso de Desporto, Universidade do Porto, Porto, Portugal, 2003. 
MAZO, J. Z. Memórias da Escola Superior de Educação Física da Universidade Federal do Rio Grande do Sul (ESEF/UFRGS): um estudo do período de sua fundação até a federalização (1940-1969). Revista Movimento, Porto Alegre, v.11, n.1, p. 143-167. Jan/abr. 2005.

MAZO, J. Z.; LYRA, V. B. Nos rastros da memória de um "Mestre de Ginástica". Revista Motriz, Rio Claro, v. 16, n. 4, p. 967-976 out./dez. 2010.

MELO, V. A. de. Escola Nacional de Educação Física e Desportos: Uma possível história. 1996. 207f. Dissertação (Mestrado) - Faculdade de Educação Física, Universidade Estadual de Campinas, Campinas.

MONTANARI, Z. R. Zilca Rossi Montanari. (depoimento, 2011). Caxias do Sul: Entrevista para a tese de doutorado intitulada "A criação da Escola Superior de Educação Física no Rio Grande do Sul: Formação de professoras(es) para a construção do campo (1940-1970)".

MORAIS, A. Anna Thereza Morais. (depoimento, 2010). Porto Alegre: Entrevista para a tese de doutorado intitulada "A criação da Escola Superior de Educação Física no Rio Grande do Sul: Formação de professoras(es) para a construção do campo (1940-1970)".

PACCINI, Q. C. L. R. C. Quintina Paccini (depoimento, 2005). Porto Alegre: Centro de Memória do Esporte - ESEFID/UFRGS, 2009. Disponível em: < http://www.lume.ufrgs. br/handle/10183/50031>. Acesso em: 2018.

PESAVENTO, S. J. História \& História Cultural. $2^{\text {a }}$ Ed. Belo Horizonte: Autêntica, 2004. PROGRAMA DE ENSINO DE BIOMETRIA. Escola Superior de Educação Física. 1940. PROGRAMA DE ENSINO DE CANTO CORAL. Escola Superior de Educação Física. 1940.

PROGRAMA DE ENSINO DE CINESIOLOGIA. Escola Superior de Educação Física. 1940.

PROGRAMA DE ENSINO DE DESPORTOS DE ATAQUE E DEFESA. Escola Superior de Educação Física. 1940.

PROGRAMA DE ENSINO DE DESPORTOS TERRESTRES COLETIVOS. Escola Superior de Educação Física. 1940.

PROGRAMA DE ENSINO DE EDUCAÇÃO FÍSICA GERAL - FEMININA. Escola Superior de Educação Física. 1940.

PROGRAMA DE ENSINO DE GINÁSTICA DE APARELHOS E LEVANTAMENTOS DE PESOS E HALTERES. Escola Superior de Educação Física. 1940.

PROGRAMA DE ENSINO DE GINÁSTICA RÍTMICA. Escola Superior de Educação Física. 1940.

PROGRAMA DE ENSINO DE METODOLOGIA DA EDUCAÇÃO FÍSICA. Escola Superior de Educação Física. 1940. 
PROGRAMA DE ENSINO DE RITMO. Escola Superior de Educação Física. 1940.

RIO GRANDE DO SUL. Decreto n. 874 de 28 de fevereiro de 1906. Reorganiza o serviço de instrucção publica do Estado. Porto Alegre: Officina Typographica do Jornal do Commercio, 1909. Documento do Arquivo Histórico do Rio Grande do Sul.

RIO GRANDE DO SUL. Decreto n. 1479 de 26 de maio de 1909. Modifica o programma do ensino complementar e CREA collegios elementares no estado. Leis, decretos e actos do Governo do Estado do Rio Grande do Sul, 1909. Porto Alegre: Officina da Livraria de Carlos Echenique, 1910. P. 207-210.

RIO GRANDE DO SUL. Decreto n. 811 de 2 de agosto de 1943. Aprova o Regimento Interno do Departamento de Educação Física. Diário Oficial do estado do Rio Grande do Sul. Porto Alegre, 5 de agosto de 1943.

SOARES, C. L. Educação Física Escolar: Conhecimento e especificidade. Revista Paulista de Educação Física, São Paulo, supl. 2, p. 6-12, 1996.

SOARES, C. L. Educação física: raízes europeias e Brasil. $2^{\mathrm{a}}$ Ed. Campinas: Autores Associados, 2001.

TARDIF, M. T. Saberes Docentes e Formação Profissional. $17^{\mathrm{a}}$ Ed. Rio de Janeiro: Vozes, 2014.

VAGO, T. M. A escolarização da Gymnastica nas Escolas Normais de Minas Gerais (18831918). In: FERREIRA NETO, A. (Org.). Pesquisa Histórica na Educação Física. Vitória: Centro de Educação Física e Desportos, 1997. Vol.2. p. 33-58.

VAGO, T. M. Estratégias de Formação de professores de Gymnastica em Minas Gerais na Década de 1920: Produzindo o Especialista. In: FERREIRA NETO, A. (Org.). Pesquisa Histórica na Educação Física. Espírito Santo: FACHA, 1999. Vol. 4. p. 51-78.

\section{NOTAS}

1 A Escola Nacional de Educação Física e Desportos (ENEFD) foi criada na Universidade do Brasil (UB), atual Faculdade de Educação Física da Universidade Federal do Rio de Janeiro (UFRJ), por meio do Decreto-Lei 1.212, no ano de 1939. Posteriormente a ela, estabeleceram-se no campo da formação de professores(as) civis de Educação Física a Escola de Educação Física e Esporte de São Paulo (1940); a Escola Superior de Pernambuco (1940) e a Escola Superior de Educação Física do Rio Grande do Sul (1940) (LYRA, 2013).

2 Optamos por manter a grafia das palavras conforme consta nos documentos históricos consultados para a pesquisa.

3 O Curso Complementar destinava-se a preparar alunos(as) candidatos(as) ao magistério público da época. Ressaltamos ainda que, no Artigo $200^{\circ}$, do Decreto n. 874, de 28 de fevereiro de 1906, destacava-se que o ensino nas Escolas Complementares deveria visar um tríplice fim: a educação physica, intellecual e moral dos alumnos (RIO GRANDE DO SUL, 1906).

4 O professor Frederico Guilherme Gaelzer foi nomeado inspetor de Educação Física, da Secretaria de Educação do estado do Rio Grande do Sul, pelo governador Getúlio Vargas, 
no ano de1929. Nesse mesmo ano, também foi nomeado professor de Educação Física da Escola Normal de Porto Alegre (BEGOSSI, 2017).

5 Sobre a presença da família Black na Educação Física do Rio Grande do Sul ver: Mazo; Lyra (2010).

6 A saber: 1) Arno Kunath - Mein verturnerbuch; Uebungen em Pferd und na den Ringen, Barrenturnen; 2) M. Ul-Leonhadt - Rock Barren; 3) Forstreuter - Gymnastik; 4) Slama Gasellscheftsuebungen; 5) Calhoffer und Streicher - Neuzeitliches Schulturnen; 6) Botta - Turngoschichte; 7) Max Schwarze - Lchregaenge in Deutschen Turner (PROGRAMA DE ENSINO DE GINÁSTICA DE APARELHOS E LEVANTAMENTOS DE PESOS E HALTERES, 1940, p. 2).

Submetido: 29/06/2018

Aprovado: 30/11/2018

Contato:

Tuany Defaveri Begossi Avenida Doutor Salvador França, 1070, apto. 405

Bairro Jardim Botânico

Porto Alegre | RS | Brasil

CEP 90.690-000 